\title{
Contributing Factors to Burnout Development in the Community Mental Health Workers
}

\author{
Geun Hui Won, MD¹, Jung Eun Kim, RN, PhD, PMHAPN², Jong Hun Lee, MD, PhD,2 \\ ${ }^{1}$ Department of Psychiatry, Daegu Catholic University School of Medicine, ${ }^{2}$ Daegu Regional Mental Health Welfare Center, Daegu, Korea
}

\begin{abstract}
Background: Burnout is a syndrome resulting from chronic work-related stress, characterized by symptoms including "feelings of exhaustion, increased mental distance from one's job, and reduced professional efficacy." Human service providers are susceptible to burnout. Thus, this study aimed to investigate community mental health workers' job stress, experiences with client violence, and burnouts and to analyze factors that affect burnout.

Methods: This study used retrospective data from a survey of mental health workers at a mental health-related institution in a city. The data included sociodemographic characteristics, job stress, client violence, and quality of life.

Results: From a total of 170 mental health workers, $67.6 \%$ were female. Subjects who were in lower age groups, had $<1$ year of work experience, were married, and were irregular workers were vulnerable to various job stressors. Factors associated with burnout were job demand, lack of reward, job insecurity, physical environment, other violence, and level of education.

Conclusion: We should create an environment wherein community mental health workers can be safe and satisfied with their work, which could lower workers' job stress and prevent burnouts due to work. This, in turn, enhances the quality of care provided to people with mental health problems.
\end{abstract}

Keywords Burnout, psychological; Occupational stress; Community psychiatry

\section{INTRODUCTION}

Burnout (BO) appears in the International Classification of Diseases 11th revision section on problems related to employment or unemployment. According to this handbook, BO is described as: 1) Feelings of energy depletion or exhaustion. 2) Increased mental distance, or feelings of negativism or cynicism related to one's job. 3) Reduced professional efficacy. However, it is important to rule out adjustment disorder, anxiety and mood disorders. Additionally, this syndrome is limited to work environments and should not be applied to other areas of a person's life [1]. In other words, although BO is not yet defined as a disorder, special care is necessary. Personality traits that are prone to $\mathrm{BO}$ include compulsivity, training in perfectionistic working environment, ten- dency to evade or deny rather than accept a difficulty, inability to accept one's weakness and tendency to overcome difficulties by being diligent and working hard [2]

'Burnout Syndrome' originated in the 1980s when a psychologist in New York named Freudenberger [3] used the term 'burn out' in his paper 'Burnout of Staffs' to explain the fatigue of professionals treating substance abusers. He coined the term to describe the symptoms observed in addiction therapists including himself. Treating patients with chronic addiction to gambling, drugs and alcohol drinking is a very cumbersome task and it is difficult to obtain tangible results in a short period of time. Therapists who used to work hard with conviction gradually becomes enervated as they see the patients unchanged despite their hard work. They pressure themselves even more, but to no avail, and at

Received February 24, 2020, Revised February 28, 2020, Accepted February 29, 2020

Correspondence: Jong Hun Lee, MD, PhD

Department of Psychiatry, Daegu Catholic University School of Medicine, 33 Duryugongwon-ro 17-gil, Nam-gu, Daegu 42472, Korea

TEL +82-53-650-4780 FAX +82-53-623-7507 E-mail rheejh@cu.ac.kr ORCID https://orcid.org/0000-0002-3581-5029

Copyright (c) by Korean Society for Affective Disorders. All Rights reserved.

This is an Open Access article distributed under the terms of the Creative Commons Attribution Non-Commercial License (http://creativecommons.org/licenses/ by-nc/4.0/) which permits unrestricted non-commercial use, distribution, and reproduction in any medium, provided the original work is properly cited. 
some point discover the exhausted self on the brink of collapse. At the same time, they develop a broad range of nonspecific physical symptoms, depressed emotional state and difficulty controlling the emotions. In his book 'Burnout: The High Cost of High Achievement,' Freudenberger [4] defined $\mathrm{BO}$ as "the extinction of motivation or incentive, especially where one's devotion to a cause or relationship fails to produce the desired results".

As its origin shows, BO is a phenomenon that occurs frequently among the group of human service providers. It has already been widely known through previous studies that human service workers undergo emotional exhaustion, depersonalization and reduced personal accomplishment [5], failure to cope with stressful situations, experience and fatigue from the frequent emotional, personal contacts while helping others, resulting in escape from work, clients and colleagues [6] and lowered participation and lack of motivation while at work or with the clients in the process of providing service [7].

Mental health workers, in particular, who have to deal with clients with mental health problems, experience not only job stress but also safety threats by clients and secondary trauma, which can accelerate the BO. Mental health worker refers to any 'working personnel' in the various occupations in mental health centers including psychiatric hospitals, mental health care facilities and psychiatric rehabilitation facilities. The ${ }^{\ulcorner}$Mental Health and Welfare Act $\lrcorner$ stipulates the qualifications and requirements of a mental health specialist and the term 'worker' is used multiple times, but not precisely defined. Mental health worker evaluates mental health problems through interactions with the client and provides therapy through early intervention and case management service. This is not only for the health and rehabilitation of individuals, but also social stabilization and economic cost reduction at the national level [8]. Creating an internal environment for the workers heightens their job satisfaction and loyalty, which in turn leads to quality services for the clients [8]. However, the reality of mental health workers is different. The workers have a hard time with low wages, heavy work load, occupational conflicts among the various occupations, secondary trauma from client suicide/violence and safety risks [9] which lead to frequent BOs and high turnover/retirement rate.

The present study thus aims to investigate the mental health workers' job stress, experience with client violence and BOs and analyze the factors affecting BO. Al- though the social role of mental health workers has expanded, previous studies on safe working environment or quality of life (QOL) tended to be biased and in fact most of the previous studies were centered on medical institutions including doctors and nurses in the psychiatry department or limited to mental health nurses among the mental health specialists [10-13]. In this study, we aimed to broaden the range of subjects by including a variety of occupational groups and evaluate the factors affecting the mental health of the workers in a diversified manner.

\section{MATERIALS AND METHODS}

\section{Subjects}

This study used data from a survey of mental health workers at mental health-related institution in a city who had understood the purpose of the survey and voluntarily agreed to participate. The survey conducted from April to August 2019 and the results were published into a survey report.

This study retrospectively used the data for public service evaluation, and the data did not include personal information that can directly identify the subject. This study was approved by the Institutional Review Board (IRB No. CR-20-027) of Daegu Catholic University.

\section{Methods}

\section{1) Sociodemographic characteristics}

The general characteristics of the participants is composed of 14 items: age, sex, marital status, religion, education, employment, work experience, occupation, workplace and institution, job description, work environment safety and satisfaction.

\section{2) Job stress}

Of the occupational stress scales for Koreans developed by the Occupational Safety and Health Research Institute [14], we used the Short form of Korean Occupational Stress Scale to measure the level of job stress. The questionnaire has a total of 24 items. Eleven negativelyworded items about the job environment were scored using a 4-point Likert scale, with 1 corresponding to 'Not at all' and 4 to 'Strongly agree.' Thirteen positivelyworded items were scored using a 4-point Likert scale, 
with 1 corresponding to 'Strongly agree' and 4 to 'Not at all.' We then calculated the total sum of the scores, greater total score indicating higher level of job stress. The reliability of the Korean version was Cronbach's $\alpha=0.76$ [14] and in this study, Cronbach's $\alpha=0.55$.

\section{3) Client violence}

The degree of violence received from client was measured using a violence assessment tool, a modified version of the Guidelines for preventing workplace violence for health care \& social service workers developed by the Occupational Safety and Health Administration [15] and revised by Choi [16]. The questions consist of a total of 16 items: 4 items on physical violence, 4 on verbal violence, 4 on sexual violence and 4 on other violence. Each item was scored using a 5-point Likert scale, with 1 corresponding to 'Never' and 5 to 'Very often' and higher score indicating greater exposure to client violence. The Cronbach's $\alpha=0.83$ in the study by Choi [16] and Cronbach's $\alpha=0.89$ in the present study.

\section{4) Korean version of the Professional Quality of Life Scale for mental health specialists}

For the professional QOL scale for mental health specialists in Korea, we used the Korean version of Professional Quality of Life Scale 5 (ProQOL 5) developed by Stamm [17], the validity and reliability of which was verified by Joo et al. [18]. The scale composed of 3 subcategories: compassion satisfaction (CS), BO, and secondary traumatic stress (STS). Each subcategory contained 10 items for a total of 30 items. Each item was scored using a 5-point Likert scale, with 1 corresponding to 'Strongly agree' and 5 to 'Very often.' Of the 10 items in BO, 5 were reversed items. For CS, higher score indicated higher CS, while for BO and STS, higher score meant higher levels of BO and STS. The reliability of the study by Joo et al. [18] was Cronbach's $\alpha=0.89$, with Cronbach's $\alpha=0.74$ for BO and Cronbach's $\alpha=0.80$ for STS. In this study, the Cronbach's $\alpha=0.90$ for CS, 0.20 for BO, 0.80 for STS and 0.71 for the entire 30 items. In this study, we used BO subcategory to analyze.

\section{Data analysis}

We used the PASW Statistics for Windows, Version 18.0 (SPSS Inc., Chicago, IL, USA) to analyze the data collected using a significance level of 0.05 for a two-sided test. We analyzed the sociodemographic characteris- tics, job stress, client violence and BO using descriptive statistics. We performed a t-test to analyze the differences in job stress, client violence and $\mathrm{BO}$ based on subject sociodemographic characteristics. We calculated the Pearson's correlation coefficients and performed multiple regression analysis to evaluate the correlation between job stress and client violence between BO.

\section{RESULTS}

\section{Sociodemographic characteristics}

A total of 170 mental health workers in the local community were analyzed. The sociodemographic characteristics of the subjects are displayed in Table 1.

Of the subjects, 55 were males (32.4\%) and 115 were females $(67.7 \%)$ and the age distribution was 73 in the $20-29$ years (42.9\%), 71 in the $30-39$ years $(41.8 \%), 14$ in the $40-49$ years $(8.2 \%)$ and 12 in the 50 years or older (7.1\%). By occupation, 20 were mental health nurses (11.8\%), 33 mental health psychologists (19.4\%), 73 mental health social workers $(42.9 \%), 8$ nurses $(4.7 \%), 4$ clinical psychologists (2.4\%), 3 social workers (17.1\%) and 3 others $(1.8 \%)$, with the mental health social workers taking up the greatest portion. By institution type, 91 workers were working in basic mental health welfare centers (53.5\%), 22 in metropolitan mental health welfare centers $(12.9 \%)$, and 57 in mental rehabilitation facilities (33.5\%). By job description, 81 workers were in severe mental illness management (47.6\%), 41 in mental health promotion (24.1\%), 8 in services for children and youths (4.7\%), 32 in suicide prevention (18.8\%), and 6 in addiction management (3.5\%). Of these, 87 were not married (51.2\%), 81 were married (47.6\%), 1 was divorced (0.6\%) and 1 was widowed $(0.6 \%)$, while 6 had graduated from college (72.9\%), 124 from university $(72.9 \%), 37$ with master's degree $(21.8 \%)$ and 3 with doctoral degree (18\%). By employment type, 83 were regular staffs $(48.8 \%)$, and 87 were irregular workers (51.2\%).

\section{Job stress, Client violence and Burnout}

We analyzed the differences in job stress (Table 2), client violence and BO (Table 3) based on the sociodemographic characteristics. We analyzed job stress (Physical environment, Job demand, Insufficient Job control, Interpersonal conflict, Job insecurity, Organizational 
Table 1. Sociodemographic characteristics of the subjects

\begin{tabular}{|c|c|}
\hline Variable & Value $(n=170)$ \\
\hline \multicolumn{2}{|l|}{ Sex } \\
\hline Male & $55(32.4)$ \\
\hline Female & $115(67.6)$ \\
\hline \multicolumn{2}{|l|}{ Age $(y)$} \\
\hline $20-29$ & $73(42.9)$ \\
\hline $30-39$ & $71(41.8)$ \\
\hline $40-49$ & $14(8.2)$ \\
\hline$\geq 50$ & $12(7.1)$ \\
\hline \multicolumn{2}{|l|}{ Occupation } \\
\hline Mental health nurse & $20(11.8)$ \\
\hline Mental health psychologist & $33(19.4)$ \\
\hline Mental health social worker & $73(42.9)$ \\
\hline Nurse & $8(4.7)$ \\
\hline Psychologist & $4(2.4)$ \\
\hline Social worker & $29(17.1)$ \\
\hline Others & $3(1.8)$ \\
\hline \multicolumn{2}{|l|}{ Institution } \\
\hline Basic mental health welfare centers & $91(53.5)$ \\
\hline Metropolitan mental health welfare centers & $22(12.9)$ \\
\hline Mental rehabilitation facility & $57(33.5)$ \\
\hline \multicolumn{2}{|l|}{ Job description } \\
\hline Severe mental illness management & $81(47.6)$ \\
\hline Mental health promotion & $41(24.1)$ \\
\hline Service for children and youths & $8(4.7)$ \\
\hline Service for suicide prevention & $32(18.8)$ \\
\hline Addiction management & $6(3.5)$ \\
\hline \multicolumn{2}{|l|}{ Marital status } \\
\hline Single & $87(51.2)$ \\
\hline Married & $81(47.6)$ \\
\hline Divorced & $1(0.6)$ \\
\hline Widowed & $1(0.6)$ \\
\hline \multicolumn{2}{|l|}{ Religion } \\
\hline No & $72(42.4)$ \\
\hline Yes & $98(57.6)$ \\
\hline \multicolumn{2}{|l|}{ Education } \\
\hline College graduate & $6(3.5)$ \\
\hline University graduate & $124(72.9)$ \\
\hline Master' s degree & $37(21.8)$ \\
\hline Doctoral degree & $3(1.8)$ \\
\hline \multicolumn{2}{|l|}{ Employment } \\
\hline Regular staff & $83(48.8)$ \\
\hline Irregular worker & $87(51.2)$ \\
\hline \multicolumn{2}{|l|}{ Work experience } \\
\hline$<1 \mathrm{y}$ & $10(5.9)$ \\
\hline $1-5 y$ & $88(51.8)$ \\
\hline $5-10 y$ & $40(23.5)$ \\
\hline$\geq 10 y$ & $32(18.8)$ \\
\hline
\end{tabular}

Values are presented as number (\%). system, Lack of reward, Occupational climate) and client violence (Physical violence, Verbal violence, Sexual violence, Others) by the sub-factors.

There were no differences between the mean values of each sub-factor of job stress (Physical environment $[p=0.230]$, Job demand $[p=0.290]$, Insufficient Job control $[p=0.110]$, Interpersonal conflict $[p=0.220]$, Job insecurity $[p=0.900]$, Organizational system $[p=0.300]$, Lack of reward $[\mathrm{p}=0.390]$, Occupational climate $[\mathrm{p}=0.950])$ and $\mathrm{BO}$ by gender. For client violence, however, males reported significantly more cases of physical violence than females $(p=0.009)$. For the interpersonal conflict of job stress, the mean value differed by age group. Post-hoc analysis revealed a difference in interpersonal conflicts at work between the 20s and 40s age groups ( $\mathrm{p}=0.001)$ and $30 \mathrm{~s}$ and $40 \mathrm{~s}$ age groups $(\mathrm{p}=0.029)$, as the $20 \mathrm{~s}$ and 30 s group reported greater job stress due to interpersonal conflict relative to the 40 s age group.

The married group reported significantly greater job stress due to occupational climate than the non-married group ( $\mathrm{p}=0.032)$ There was no significant difference in job stress, client violence and BO with or without religion. Workers with higher level of education (master's or doctoral degree than university-graduate) reported more BOs $(\mathrm{p}=0.047)$.

Irregular workers were shown to be under greater job stress than regular staffs due to physical environment $(<0.001)$, job insecurity $(<0.001)$ and occupational climate $(p=0.042)$. The mean value of interpersonal conflict and physical violence differed by work experience. The post-hoc analysis showed that interpersonal conflict was highest in the $<1$ year of experience than in all other groups; $1-5$ years of experience ( $p=0.002), 5-10$ years of experience $(\mathrm{p}=0.001)$, and 10 years of experience or over 10 years of experience $(<0.001)$. Physical violence was reported to be lower in the $<1$ year of working experience group, which suggests that client violence is first experienced between 1-5 years of work and there is no significant increase afterwards.

\section{Correlation between burnout and subfactors of job stress and client violence}

We analyzed the correlation between the subfactors of job stress and client violence and BO (Table 4). BO was correlated with various subfactors of job stress: physical environment $(<0.001)$, job demand $(<0.001)$, insufficient job control $(<0.001)$, job insecurity $(<0.001)$, lack of re- 


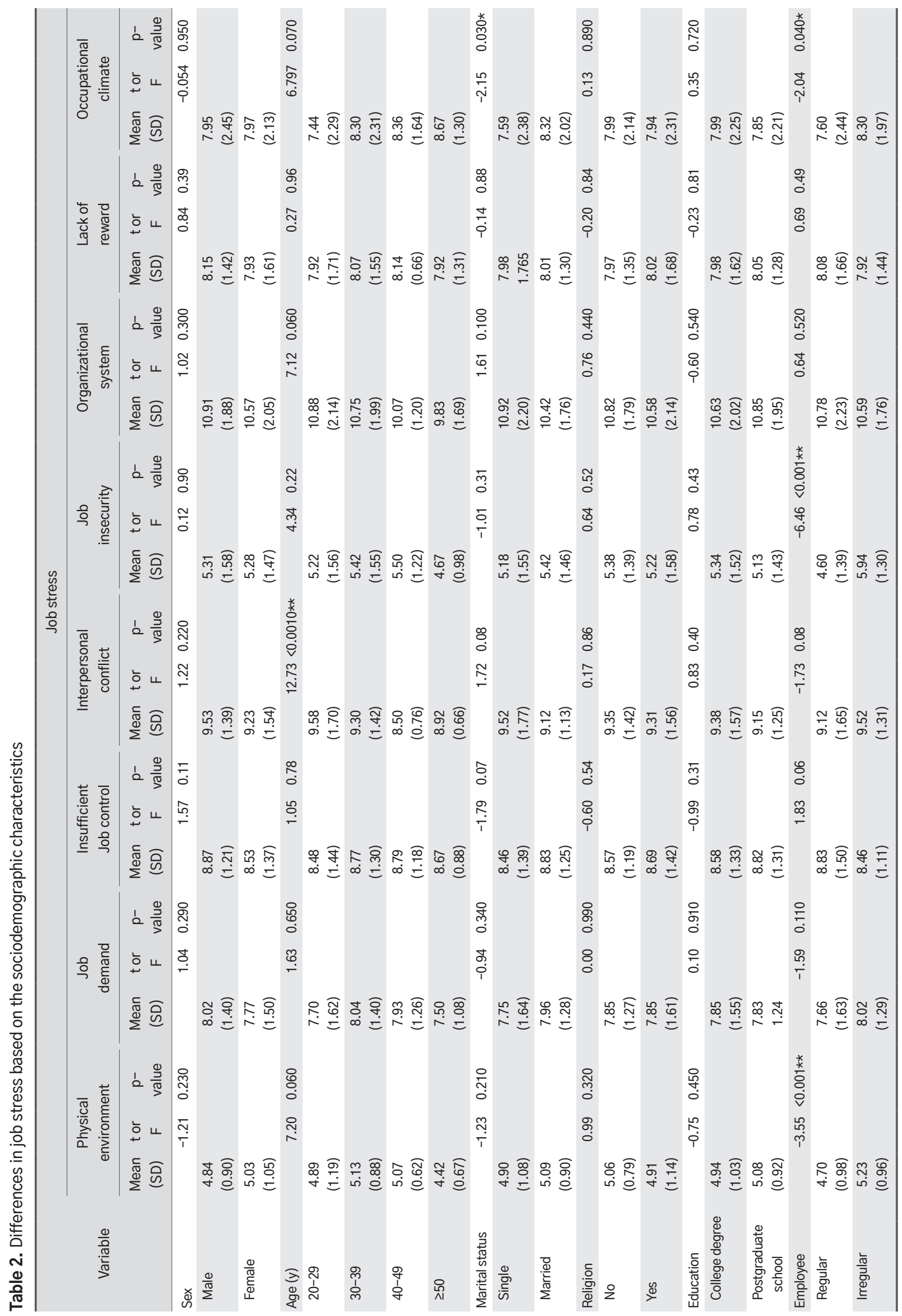




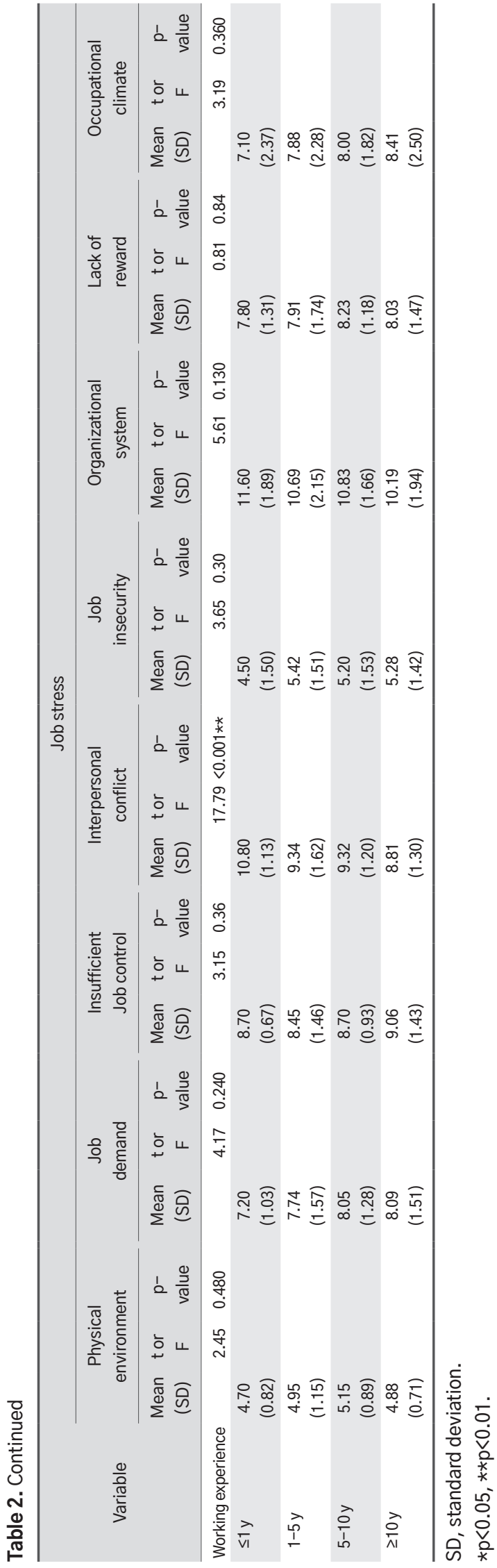

ward $(p=0.005)$, organizational system $(p=0.009)$.

All four subfactors of client violence were correlated with BO: physical violence $(<0.001)$, verbal violence $(<0.001)$, sexual violence $(\mathrm{p}=0.001)$ and other violence $(<0.001)$.

\section{Multiple Regression analysis to identify the determinants of burnout}

We performed multiple regression analysis on the previous analytic results to determine the final factors affecting $\mathrm{BO}$ in mental health workers (Table 5). The results revealed job demand $(<0.001)$, other violence $(\mathrm{p}=0.003)$, lack of reward $(<0.001)$, job insecurity $(p=0.004)$, physical environment $(p=0.022)$ and level of education $(\mathrm{p}=0.022)$ as the factors associated with $\mathrm{BO}$.

\section{DISCUSSION}

This study aimed to investigate the level of job stress, experience with client violence and $\mathrm{BO}$ by analyzing the results of the survey conducted on mental health workers at mental health-related institutions. Moreover, we aimed to analyze the factors affecting the $\mathrm{BO}$ in community mental health workers. A total of 170 mental health workers in the local community was subject to analysis, of which $67.6 \%$ were females and $84.7 \%$ were in their 20-30s. Most subjects had high education status with a college degree or higher and more than half had 1-5 years of work experience.

Subjects who were in the lower age groups, had $<1$ year of work experience, were married and were irregular workers were vulnerable to various job stresses.

For subjects in the lower age groups (20s and 30s) and with $<1$ year of work experience, interpersonal conflicts ('My boss do not help me to complete the task', 'My colleagues do not help me with the task', 'When I am having a hard time at work, there are no people who recognize and understand that I am.') acted as job stress.

In addition, irregular workers experienced greater job stress than regular staffs in terms of physical environment ('My job is dangerous and there is a possibility of an accident', 'My work requires maintaining an uncomfortable posture for a long time'), job insecurity ('I am uncertain about my future at work because of unstable working conditions', 'There was or will be an undesirable change in my working conditions or circum- 


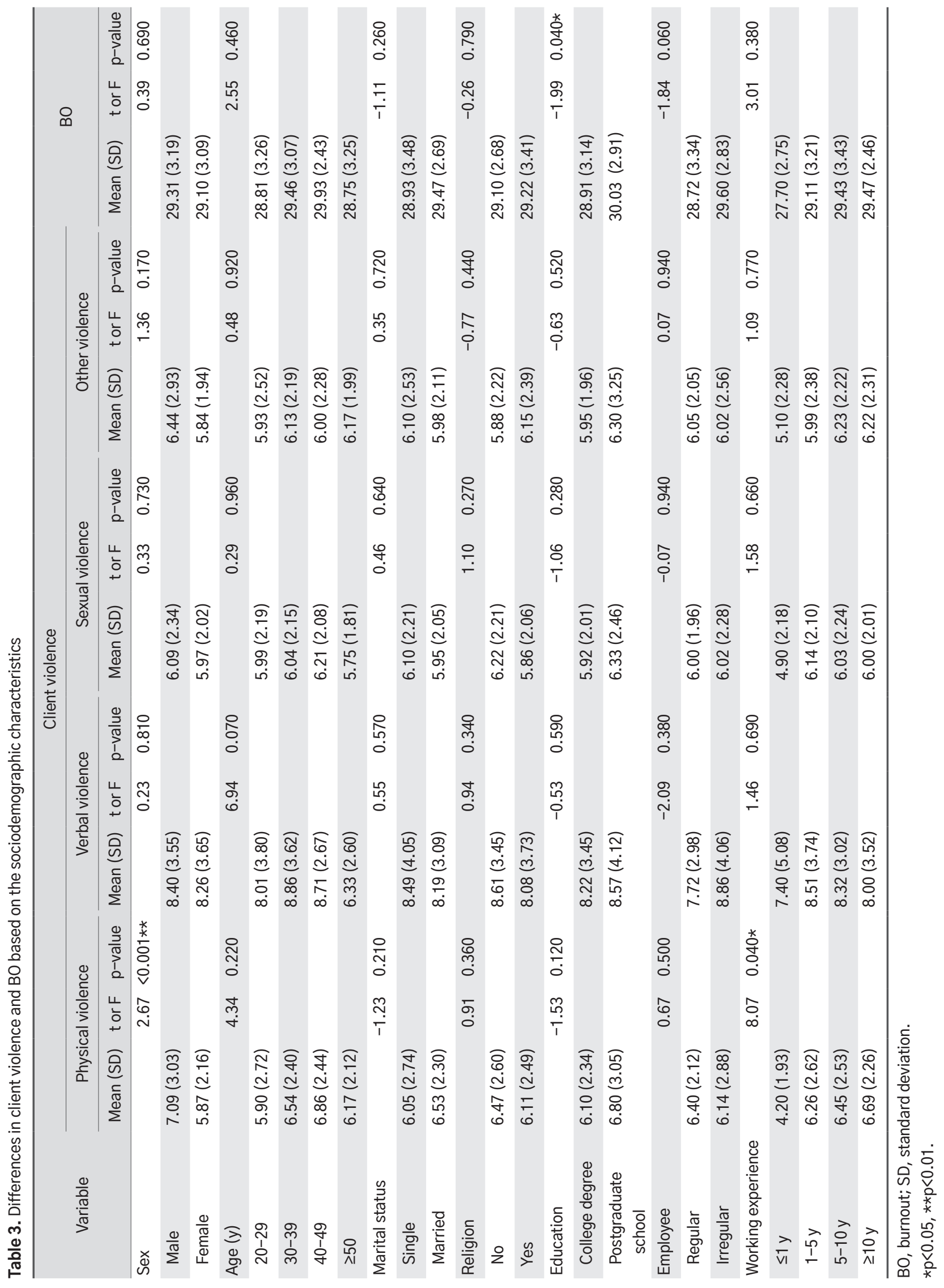




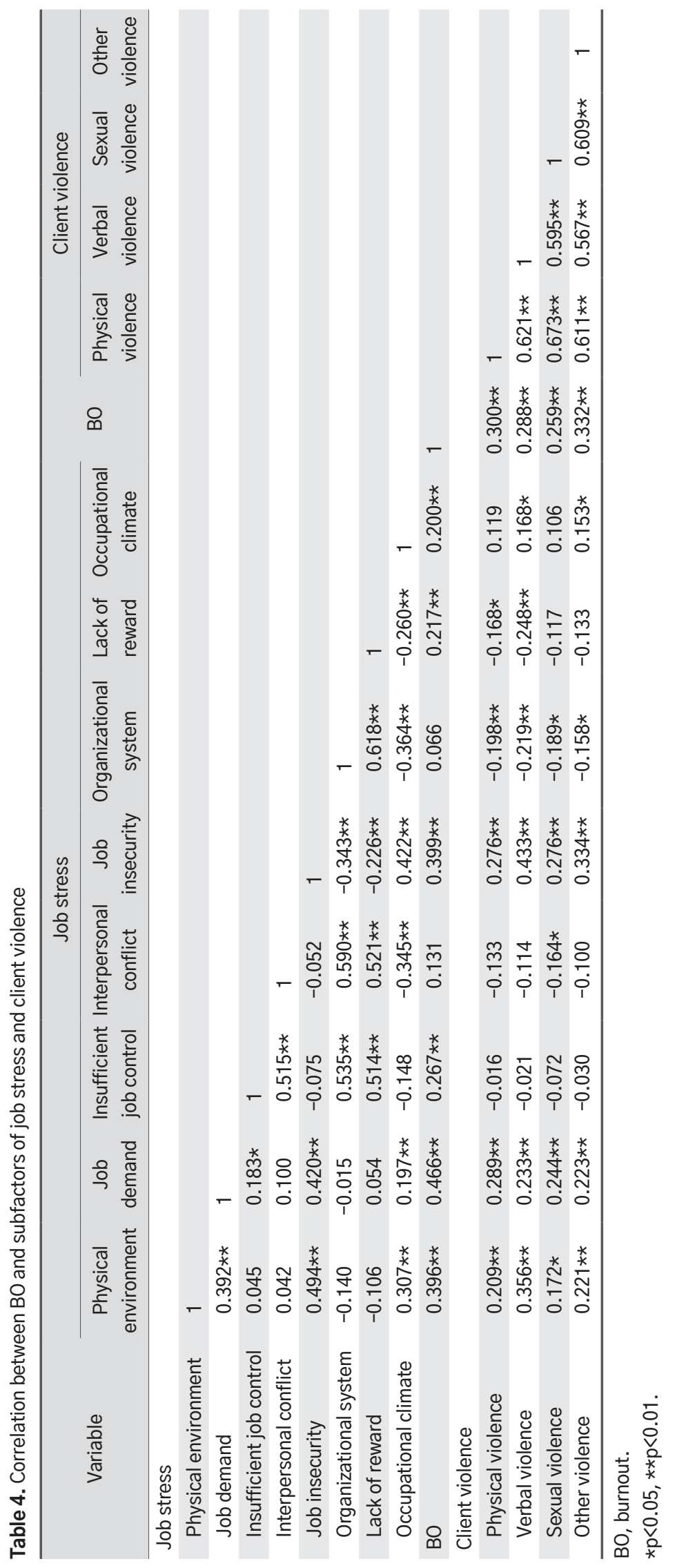


Table 5. Factors associated with BO in community mental health workers

\begin{tabular}{|c|c|c|c|c|c|}
\hline Variable & B & SE & $\beta$ & $\mathrm{t}$ & $p$-value \\
\hline \multicolumn{6}{|l|}{ Job stress } \\
\hline Job demand & 0.52 & 0.14 & 0.24 & 30.59 & $<0.001 * \star$ \\
\hline Lack of reward & 0.59 & 0.12 & 0.29 & 40.69 & $<0.001 * \star$ \\
\hline Job insecurity & 0.45 & 0.15 & 0.22 & 20.89 & $0.004 * \star$ \\
\hline Physical environment & 0.51 & 0.22 & 0.16 & 20.31 & $0.022 *$ \\
\hline \multicolumn{6}{|l|}{ Client violence } \\
\hline Other violence & 0.26 & 0.08 & 0.19 & 30.04 & $0.003 * *$ \\
\hline \multicolumn{6}{|c|}{ Sociodemographic characteristics } \\
\hline Education & 10.02 & 0.44 & 0.14 & 20.30 & $0.022 \star$ \\
\hline
\end{tabular}

BO, burnout; $B$, unstandardized beta coefficients; SE, standard error; $\beta$, standardized beta coefficients.

Dependant variable: $\mathrm{BO}$.

$\star p<0.05, * * p<0.01$.

stances'), organizational system ('I am uncomfortable at company dinners', 'I get inconsistent work orders with no standards', 'The organizational culture is authoritative and hierarchical', 'There is discrimination based on male-female gender differences'). Married subjects reported greater job stress due to occupational climate than those not married.

Multiple regression analysis showed that the final determinants of $\mathrm{BO}$ were job demand ('I am always pressed for time due to overwhelming work load', 'The amount of work has significantly increased', 'I don't get enough rest during work'), lack of reward ('Given all my efforts and accomplishments, I am not getting the respect and trust I deserve at work', 'I feel tired from work because my situation won't get better in the future'), job insecurity, physical environment, other violence (client stalking, formal complaint and lawsuit, calling or stalking to the extent that it interferes with work, property damage-theft and extortion of money-by client) and level of education. This fits the definition of BO: a highly educated person (level of education) who had started out with high ideals is placed in a dangerous (physical environment) and unstable (job insecurity) environment that falls short of one's expectations and struggles to work beyond his or her capacity (job demand), only to be faced with not adequate reward (lack of reward) but personal threats (other violence) and becomes burnt out.

In fact, the above factors have been addressed in previous studies on BOs. The term "presenteeism" is a compound word created by adding the suffix "-ism" that signifies action and result to the adjective "present," meaning 'showed up' or 'attended' [19]. Presenteeism refers to working despite poor health [20] and the resulting loss of productivity [21]. It has been confirmed that high levels of job demand or work load affects BO and presenteeism [22]. It has also been reported that occupational stresses including job demand (personal work, excessive workload, etc.) and inadequate reward is linked to presenteeism $[23,24]$.

On the other hand, evaluation of the relative influences of different variables that can increase occupational $\mathrm{BO}$ in police officers revealed that organizational system has the greatest influence on BO, followed by interpersonal conflict and job demand [25]. In our study, organizational system and interpersonal conflict were not selected as the final determinant of $\mathrm{BO}$, which suggests that there are various factors of $\mathrm{BO}$ depending on the organization and thus intervention must take place according to the organizational culture and characteristics.

Meanwhile, job insecurity affected BO in mental health workers. According to a study of sports instructors for the disabled conducted in 2018, welfare at work, a subcriteria of job insecurity, significant affected all subfactor of BO syndrome including exhaustion, cynicism and decreased job efficacy [26].

Client violence was positively correlated with job stress and low QOL, which is consistent with previous studies of medical staffs who had experienced violence. According to a study on the psychiatric ward nurses' experience with violence and $\mathrm{BO}$, nurses in psychiatric wards experience more physical threats and violence from patients than nurses in general wards and such experience with violence increased BO. On the other hand, 
less experience with violence or higher self-expression ability led to decreased levels of BO [11]. In another study on the emergency room staffs' experience with violence and difference in levels of stress and depression, $86.7 \%$ of ER staffs were exposed to violence in the workplace and the group that had experienced physical violence within 1 year scored higher in the levels of stress and depression [27]. In the present study, however, other violence than physical/verbal/sexual violence was found to be the final determinant of BO, which may be explained by the fact that other violence is linked to more direct harms like stalking, property damage and complaint/lawsuit.

Regarding occupational BO by education level, results are varied. A study of geriatric care providers showed that elderly care was provided mostly by younger female workers with shorter history of work experience. Although the average education level was relatively high, the problem of low wage and high workload was severe. Moreover, it has been shown that lower age and higher education level corresponded with higher workload and $\mathrm{BO}$ [28]. On the other hand, there are also contradictory findings that education level has no correlation to $\mathrm{BO}$ [29] or that lower education level is correlated with lower level of BO [30]. This can be explained by the differences in duration for dividing the education level. In this study, most of the mental health workers were highly educated and level of BO was highest in subjects who had graduated from graduate school to obtain a master's or doctoral degree. Since BO occurs when a given job does not meet the expectations of individual and society, it is likely that the working conditions and accomplishments that fail to meet the expectations of the individuals have affected their BO status. Furthermore, the personality traits of individuals attending graduate school may also have played a part.

Then, we can also infer the factors that deter the occurrence of $\mathrm{BO}$ in community mental health workers, which are provision of safe and sound working environment that meet individual expectations, appropriate distribution of workload based on individual capacity, sufficient physical/psychological reward and protection from harm during work.

This study has the following limitations. First, since the study targets mental health workers in a City, the results may not be generalized to the entire population of mental health workers. However, according to a research on the current state of full-time workers at community rehabilitation centers, $20 \%$ were mental health nurses, mental health clinicians 3\%, mental health social workers $40 \%$, nurses $9 \%$, clinical psychologists $1 \%$ and social workers $22 \%$, which is similar to the results of the present study, except for the clinical psychologist category: mental health nurses $11.8 \%$, mental health clinicians $19.4 \%$, mental health social workers $42.9 \%$, nurses $4.7 \%$, clinical psychologists $2.4 \%$ and social workers $17.1 \%$ [31].

Second, we assessed the correlation between client violence, job stress and $\mathrm{BO}$, but did not take into account other factors like depression that can affect all three of these.

Third, we did not survey the protective factors of BO. In fact, there has been reports that factors like individual optimism [32], emotional intelligence [33] and resilience [34] are negatively correlated with psychological BO.

Despite these limitations, the present study is needed at a time when the safe work environment of mental health workers is being threatened. The study is valuable in that it not only targets the staffs at medical institutions, who have been the main focus of previous studies, but also the community mental health workers who are the first to contact the patients with mental health problems and perform overall investigation of the status quo and evaluate the levels of client violence, job stress and $\mathrm{BO}$ in the workplace.

\section{CONCLUSION}

We have to create an environment for the community mental health workers to be safe and satisfied with their work, which can lower the job stress of the workers and prevent BOs due to work. This in turn leads to enhanced quality of care provided to people with mental health problems and hopefully reduces the social prejudice and stigma against the mentally ill. This will require various efforts, such as creating a working environment and regulating the workload so that individuals can properly realize their potentials, deviating from the tendency to take for granted the violence experienced by mental health workers and staying alert and strengthening supervision so that the violence experienced by mental health specialists does not become a trauma. 


\section{CONFLICTS OF INTEREST}

The authors have nothing to disclose.

\section{ACKNOWLEDGEMENTS}

This study used data from the survey conducted by Daegu Metropolitan Mental Health Center. The survey published into the report 'A Survey Report on Safety and Burnout Prevention of Mental Health Workers in Daegu Area'.

\section{ORCID}

Geun Hui Won
https://orcid.org/0000-0003-1220-6674
Jung Eun Kim
https://orcid.org/0000-0002-2787-6729
Jong Hun Lee
https://orcid.org/0000-0002-3581-5029

\section{REFERENCES}

1. World Health Organization. Burn-out an "occupational phenomenon": International Classification of Diseases [Internet]. Geneva: World Health Organization; 2019 May 28 [cited 2019 Jun 13]. Available from: https://www.who.int/ mental_health/evidence/burn-out/en/.

2. Patel RS, Bachu R, Adikey A, Malik M, Shah M. Factors related to physician burnout and its consequences: a review. Behav Sci (Basel) 2018;8:E98.

3. Freudenberger HJ. The staff burn-out syndrome in alternative institutions. Psychotherapy 1975;12:73-82.

4. Freudenberger HJ, Richelson G. Burn-out: the high cost of high achievement. New York: Bantam Books; 1981.

5. Maslach C. The client role in staff burn-out. J Soc Issues 1978;34:111-24.

6. Muldary TW. Burnout among health professionals: manifestations and management. Norwalk: Appleton-CenturyCrofts; 1983.

7. Corcoran KJ, Bryce AK. Intervention in the experience of burnout: effects of skill development. J Soc Serv Res 1983; 7:71-9.

8. Heskett JL, Jones TO, Loveman GW, Sasser WE, Schlesinger LA. Putting the service-profit chain to work. Harv Bus Rev 1994;72:164-74.

9. Lim HY. A study on the effects of internal service quality on job embeddedness at community mental health center
[MD thesis]. Seoul: Sungkyunkwan University; 2015.

10. Rossi A, Cetrano G, Pertile R, Rabbi L, Donisi V, Grigoletti L, et al. Burnout, compassion fatigue, and compassion satisfaction among staff in community-based mental health services. Psychiatry Res 2012. doi: 10.1016/ j.psychres.2012.07.029. [Epub ahead of print]

11. Yun YK. A study on the correlation between violence experience, assertiveness and burnout of nurses working in psychiatric wards [MD thesis]. Seoul: The Graduate School of Ewha Womans University; 2010.

12. Lee SN, Yoo EK. A phenomenological study on experience of clinical supervision by psychiatric mental health nurse practitioners. J Korean Acad Psychiatr Ment Health Nurs 2017;26:174-85.

13. Jeong C, Lee EN. Mediating effect of resilience on the association between violence experience and violence response among nurses. J Korean Acad Soc Adult Nurs 2018;30:41-8.

14. Chang S, Kang D, Kang M, Koh S, Kim S, Kim S, et al. Standardization of job stress measurement scale for Korean employees: the 2nd year project. Incheon: Occupational Safety and Health Research Institute; 2004.

15. Occupational Safety and Health Administration. Guidelines for preventing workplace violence for health care and social service workers. Washington: US Department of Labor; 2004.

16. Choi SC. Survey on the risk management of workers in welfare facilities. Seoul: Seoul Welfare Foundation; 2005.

17. Stamm B. The ProQOL (Professional quality of life scale: compassion satisfaction and compassion fatigue). In: Stamm B, ed. The concise ProQOL manual. 2nd ed. Pocatello: ProQOL.org; 2010.

18. Joo H, Cho Y, Ahn H. Validation of the Korean version of professional quality of life scale 5(K-ProQOL 5) for mental health professional. Cognit Behav Ther Korea 2016;16:26998.

19. Lee K, Kim Y, Lee K. Relationships among burnout, presenteeism, and coaching achievement in athlete coaches. Korean J Sport Sci 2019;30:34-44.

20. Aronsson G, Gustafsson K, Dallner M. Sick but yet at work. An empirical study of sickness presenteeism. J Epidemiol Community Health 2000;54:502-9.

21. Turpin RS, Ozminkowski RJ, Sharda CE, Collins JJ, Berger ML, Billotti GM, et al. Reliability and validity of the Stanford Presenteeism Scale. J Occup Environ Med 2004;46:1123-33.

22. Demerouti E, Le Blanc PM, Bakker AB, Schaufeli WB, Hox J. Present but sick: a three-wave study on job demands, presenteeism and burnout. Career Dev Int 2009;14:50-68.

23. Jeon SH, Leem JH, Park SG, Heo YS, Lee BJ, Moon SH, et al. Association among working hours, occupational stress, and presenteeism among wage workers: results from the Second Korean Working Conditions Survey. Ann Occup Environ Med 2014;26:6.

24. Prater T, Smith K. Underlying factors contributing To pre- 
senteeism and absenteeism. J Bus Econ Res 2011;9:1-14.

25. Kim SH. The relative influence of job stress on burnout of police officers according to the type of work. Soc Sci Stud 2015;22:259-78.

26. Sim YK, Kim JT. Effect of job insecurity of disability sports instructor on burnout syndrome. Korean J Adapt Phys Act 2018;26:93-104.

27. Kim JH, Choi HS, Jung HJ, Lim SG, Lee CM. Workplace violence experienced by emergency department workers and its association with stress and depression assessment. J Korean Soc Emerg Med 2019;30:257-64.

28. Choi HK. A study on factors affecting burnout of staffs taking care of elders in nursing facilities. J Korea Gerontol Soc 2008;28:157-76.

29. Kim JH, Choi MK. Relationship among child care teachers` personal characteristics, emotional labor, and burnout.
J Eco-Early Child Educ 2013;12:51-68.

30. Lee JH, Cho SY. The effect of ego-resilience and directors, co-workers and family`s social support to childcare teachers` burnout. Korean J Child Stud 2011;32:157-72.

31. Jun J, Lee N, Kim J. Recent changes in mental health policy in Korea. Health Welf Policy Forum 2017;246:51-63.

32. Scheier MF, Carver CS, Bridges MW. Distinguishing optimism from neuroticism (and trait anxiety, self-mastery, and self-esteem): a reevaluation of the Life Orientation Test. J Pers Soc Psychol 1994;67:1063-78.

33. Cho HJ, Park KA. The effect of emotional intelligence and self-efficacy on teachers' burnout. J Korean Teach Educ 2007;24:251-70.

34. Kang JS, Lim JY. Effects of clinical nurses' resilience on job stress and burnout. J Korea Contents Assoc 2015;15:263-73. 